\title{
VIEWPOINT
}

\section{Blockchain and the resurrection of consumer sovereignty in a sustainable food economy}

\author{
Jeff Schahczenski a* \\ National Center for Appropriate Technology \\ Celia Schahczenski b \\ Montana Technological University
}

Submitted February 13, 2020 / Revised February 20, 2020 / Accepted February 22, 2020 /

Published online May 19, 2020

Citation: Schahczenski, J., \& Schahczenski, C. (2020). Blockchain and the resurrection of consumer sovereignty in a sustainable food economy. Journal of Agriculture, Food Systems, and Community Development, 9(3), 79-84. https://doi.org/10.5304/jafscd.2020.093.028

Copyright (C) 2020 by the Authors. Published by the Lyson Center for Civic Agriculture and Food Systems. Open access under CC-BY license.

Consumption is the sole end and purpose of all production; and the interest of the producer ought to be attended to, only so far as it may be necessary for promoting that of the consumer. The maxim is so perfectly selfevident, that it would be absurd to attempt to prove it.

-Adam Smith, An Inquiry into the Nature and Cause of the Wealth of Nations (1776)

\footnotetext{
a $*$ Corresponding author: Jeff Schahczenski is an agricultural and natural resource economist with the National Center for Appropriate Technology and specializes in crop insurance, organic and sustainable economics and marketing, and biotechnology. He can be reached at jeffs@ncat.org.

b Celia Schahczenski is professor of computer science with expertise in data science, data integration and warehousing, formal methods, net neutrality, and the assurance of an open and democratic Internet. She can be reached at cschahczenski@mtech.edu.
}

\section{Introduction}

In today's global food system, where the concentration of both economic and political power is self-evident, the maxim of consumer sovereignty is in great need of proof. In Montana, where we live, we have the great fortune to buy grass-finished certified organic beef from a rancher almost literally in our own backyard. We know the supplier of our food not only as a producer, but as a friend. This rancher can easily garner from us, and his other costumers, our preferences. In a sense, we drive the rancher's production methods and pricing. Even though we insist on organic certification, it is largely on the basis of trust and friendship that we

Authors' Note Regarding Implication from COVID-19 This viewpoint was written before the pandemic, but blockchain supply-chain management is likely to become a topic of more importance as we move beyond the pandemic. 
return to purchase from him over and over for our family's beef supply.

Our local oligopolistic supermarket chain ${ }^{1}$ also carries certain cuts of grass-finished certified organic beef. When we purchase our beef there, we have no sense of where and who produced the beef. Furthermore, we do not know how much of the price we pay ultimately ends up in the hands of the rancher who produced it. We have little reason to trust that this price is fair to that rancher.

What if recent developments in information technology could provide us the assurance of not only knowing the how, who, and where of our certified organic grass-finished beef, but also of the fairness of return to the rancher? Would we as consumers utilize this knowledge? Would we prefer products in which fairness of return to the producer is known over products where return to the producer is unknown? Would we purchase products from local producers over products whose origin is unknown? Would this information alleviate the real problems of concentrated economic and political power in our food system? Could technology restore customer sovereignty? According to some, blockchain technology could turn out to be a disruptive technology that not only increases efficiency and reduces costs, but also changes the way food is distributed and consumed (Constantinides, Henfridsson, \& Parker, 2018; The Economist, 2015).

\section{What Is Blockchain?}

One good and fairly recent (2016) definition of blockchain is:

a distributed database of records, or public ledger of all transactions or digital events that have been executed and shared among participating parties. (Crosby, Nachiappan, Pattanayak, Verma, \& Kalyanaraman, 2016, p. 8)

While this seems fairly straightforward, putting these ideas into practice is complicated. There are two important elements in the above definition of blockchain technology.

First, blockchain is a distributed database, often referred to as a distributed ledger system of transactions or digital events. In the case of a food supply chain, each party in the supply chain can add transactions into a "ledger" of information. Example transactions are "birth of calf \#7888231 on ranch \#5555 on dd/mm/yy," "loading of yearling \#7888231 from ranch \#555 onto transport \#6666 on dd/mm/yy," and "arrival of yearling \#7888231 at processing facility \#7777 on $\mathrm{dd} / \mathrm{mm} /$ yy." Each actor involved in supplying a product to a consumer adds their transaction, via manual data entry, a cow tag reader, or some other type of sensor, to the ledger. No one actor is required to "own" the ledger. Instead, the ledger tracks the supply chain, so that all actors can interact with it, and, to the extent that correct data is entered, consumers can see the process that led to bringing that product to their shopping basket. Some assert that the blockchain distributed ledger systems enhance complex supply chain management while creating trust-embedded systems with increased transactional efficiency and transparency. This allows consumers greater access to highly differentiated and identity-preserved products whose provenance is clear and trusted (Jouanjean, 2019; Hawlitschek, Notheisen \& Teubner, 2018). Recent authors also claim that blockchain can clarify how economic value is shared from farmer to consumer (Tripoli \& Schmidhuber, 2018). It is this point that is most relevant to consumer sovereignty.

Second, blockchain allows sharing among participating parties, but once ledger values are entered, participants cannot change them. This inability to alter ledger data is referred to as immutability. This provides the security of the blockchain, so much so that blockchain is the technology behind several crypto-currencies such as Bitcoin.

The term "cryptology" is similar to the idea of a secret code. Each transaction in the blockchain supply-chain is both verified by other members (known as a distributed consensus) and protected by an

\footnotetext{
${ }^{1}$ The average market share of the top four food retailers (known as CR4) was 63\% for 2014 across 27 U.S. Metropolitan Statistical Areas (Ma, Saitone, Volpe, Sexton, \& Saksena, 2019). A CR4 greater than 60\% demonstrates significant market power where these four firms may coordinate prices and output, creating an oligopolistic market (Connor, Rogers, Marion, \& Mueller, 1985).
} 
embedded security system (Casado-Vara, Prieto, De la Prieta, \& Corchado, 2018). Thus, it is very easy to trace where a break or misinformation in the blockchain system has occurred and, at the same time, very difficult for any member within or outside of the blockchain to hack into the information being exchanged.

The idea of a public ledger in this definition is a bit of a misnomer. Whether the information within a blockchain is public is, of course, dependent on what the blockchain is being used for. One major retail supermarket chain uses blockchain for traceability of produce through its complex supply chain. However, the information embedded in the blockchain is not for general public consumption, nor even necessarily for the farmer providing products to the food retailer. These are referred to a permissioned blockchains (VeChain, 2020). On the other hand, other blockchain systems are purposefully public in nature. For example, an innovative blockchain system called BeefChain ${ }^{2}$ is explicitly public so that the beef consumer can buy identity-preserved Wyoming beef from a select set of ranchers. Even here, not all information collected within the blockchain is public. However, if consumers increasingly demand information concerning the safety of their food, its origin, and the sustainability of the processes that have produced and delivered it, blockchain technology may be gaining momentum in food supply chain management and product promotion (Schahczenski, 2019).

\section{Beyond Traceability to Full Transparency}

The use of blockchain for food safety and general supply-chain management has been the topic of several research efforts (Galvez, Mejuto, \& SimalGandara, 2018; Sander, Semeijn, \& Mahr, 2018). Part of the discussion here regards whether blockchain technology can assist with the many confusions that are created by a proliferation of labels. Also, can the consumer "trust" labels? When a meat product is labeled "grass-fed," is the consumer sure that, in fact, the ruminant was grass-fed its entire life? The claim by these researchers is that blockchain technology can "solve" this problem by "ensuring credible and reliable product information through the entire meat supply chain, from farm to fork" (Sander et al., 2018, p. 2079).

Blockchain applied to supply chain management has also been studied in relation to transaction costs. Through blockchain technology, transaction costs can likely be lowered and therefore create greater economic value (Mettler, 2016). While similar to the broader topic of "smarter and more accessible data and market information," traceability and identity preservation blockchain efforts are an intentional effort to use blockchain as a disruptive technology (Tripoli \& Schmidhuber, 2018).

One recent agricultural example of this "disruption" is the claim by a start-up Canadian firm, Grain Discovery, in executing the first field corn transaction using blockchain (Grain Discovery, 2019). The transaction was interesting because the original sale of the corn in question was rejected by the farmer's traditional buyer because it tested for a slightly high level of vomitoxin (caused by mold on corn). Grain Discovery was able to facilitate a new buyer quickly using its blockchain platform. More broadly, Grain Discovery claims that it is:

focused on untangling the complicated supply chain paths for grains. The Grain Discovery platform gives more control to both farmers and buyers and has endless applications, from allowing consumers to see the path their food travelled, to calculating the carbon intensity behind the production of food and biofuels. (Grain Discovery, 2019, para. 7)

But this disruption of making clear the provenance of products through complicated agriculture and food supply-chains more transparent to end buyers and consumers does not often include discussion of how economic value flows through these same blockchain systems. Wouldn't economic value transparency be even more disruptive than simply knowing how and where my Thanksgiving turkey was produced and how it was slaughtered, processed, transported, and handled before I purchased it?

2 https://beefchain.com/ 


\section{Fair Trade and Blockchain}

The fair trade movement has tried for many years to improve the relative economic power and viability of very poor small farmers in developing counties. While they have used label programs and other efforts, blockchain appears to be a natural fit for this movement. Indeed, a new effort by the FairChain Foundation is undertaking just such an effort with coffee growers in Ethiopia (Academics for Development, n.d.). This project allows consumers of this coffee to see verified data on the difference between the local market price that the producer would have received for the coffee, and the actual and improved priced received by the farmers entering into the fair trade arrangement of this project. By using a brand developed App and scanning a QR (Quick Response) code on the final product, a consumer living thousands of miles away can verify the real economic benefit to the coffee farmer from their purchase.

While this project represents a major step up in expanding blockchain to a better reckoning of economic value through a complex food supply chain, the economic benefit is dependent on the unique case of a specific brand of a very high-end, singleorigin coffee that can command a higher price differential. It seems that the fair trade movement may not have yet fully embraced blockchain technology, and it appears to hold to a somewhat narrow understanding of the full potential of the technology. In a 2019 Fairtrade Foundation blog post, Catherine Thompson warned of a need for a maturing of the technology. However, she did see the possibility of blockchain for "democratizing the information in [food] supply chains" (Thompson, 2019). She went on to say:

Farmers often have to share lots of information about themselves but don't receive any information in return. If systems were built in the right way, it [sic] could support farmers to understand the journeys their crops takepotentially helping them to better manage their customer relationships and risks-and ultimately become more resilient. (Thompson, 2019, para. 5)

Could the economic and ecological resiliency of the Ethiopian coffee farmer just be a matter of an information imbalance corrected by blockchain technology?

\section{Summary: Sovereignty Regained?}

One of the major blockchain platforms claims that blockchain is a technology that "will only thrive and achieve mass adoption if it can add value to businesses and make the world a better place." (VeChain, 2020). Does a better world include an outcome where consumers can express new sovereignty over the production of food controlled by powerful political and economic actors in the global, national, and even local food systems? The Ethiopian coffee grower's case suggests that this may be possible.

Many food and agriculture companies still use information systems, supported by centralized databases, to effectively track significant aspects of their processes and products. Blockchain technology shines when processes involve multiple organizations. Confusion as to where the product contamination occurred and the ability to find "niche" markets for contaminated grains in the case of Grain Discovery, and even the carbon intensity behind grain production, cannot easily be captured by a single centralized database.

We suggest that blockchain technology has the potential to be a truly disruptive technology if attention is placed on sharing economic value from farmer to consumer. While not needed when one is close to the actual producer of their food, where trust does not need to be embedded in a blockchain, most consumers are separated from the production and may appreciate knowing more about the farmer or rancher. Whether local and regional food systems can utilize the blockchain to choose to support producers will be a function of its cost to implement and, more importantly, whether customers in these systems will pay the needed higher price to fully reward the farmers and rancher who participate in that food system.

How interesting would it be if sitting down at our local restaurant or, better yet, our local fastfood chain, we could take out our smartphones and read a code on the menu that would provide not only truthful information about how our food was raised, but how much of the value we pay for 
the item is returned to the farmer? Could a new era of product competition be emerging where we can buy products for multiple important values, including supporting our local and regional economy and the farmer or rancher who did the bulk of the work to provide us with something so very good? Perhaps we need to reassess what is both the real and just price of food. Maybe blockchain technology could help enormously with that assessment. We share with others the hope that blockchain will change "the perception of value" and that "within a certain techno-economic context, is instrumental to unlock the potential for societies to prosper" (Pazaitis, De Filippi, \& Kostakis, 2017, p. 106).

\section{References}

Academics for Development. (n.d.). FairChain Foundation. Retrieved February 2020 from the Academics for Development website: http://afdimpact.org/projectname/fairchain-foundation-18-19/

Casado-Vara, R., Prieto, J., De la Prieta, F., \& Corchado, J. M. (2018). How blockchain improves the supply chain: Case study alimentary supply chain. Procedia Computer Science, 134, 393-398. https://doi.org/10.1016/j.procs.2018.07.193

Connor, J. M., Rogers, R. T., Marion, B. W., \& Mueller, W. F. (1985). The food manufacturing industries: Structures, strategies, performance, and policies. Lexington, MA: DC Heath.

Constantinides, P., Henfridsson, O., \& Parker, G. G. (2018). Introduction-Platforms and infrastructures in the digital age. Information Systems Research, 29(2), 381-400. https://doi.org/10.1287/isre.2018.0794

Crosby, M., Nachiappan, Pattanayak, P., Verma, S., \& Kalyanaraman, V. (2016). Blockchain technology: Beyond bitcoin. Applied Innovation Review, (2), 7-19. Retrieved from https://www.appliedinnovationinstitute.org/blockchain-technology-beyond-bitcoin/

Economist, The. (2015, October 31). The promise of the blockchain: The trust machine. The Economist. https://www.economist.com/leaders/2015/10/31/the-trust-machine

Galvez, J. F., Mejuto, J. C., \& Simal-Gandara, J. (2018). Future challenges on the use of blockchain for food traceability analysis. Trends in Analytical Chemistry, 107, 222-232. https://doi.org/10.1016/j.trac.2018.08.011

Grain Discovery. (2019, January 16). Grain Discovery executes world's first corn trade using blockechain [Press release]. Retrieved from https:// us7.campaign-archive.com/?u=d7bbcb66546cdec062f65fdfc\&id=6172117d8a

Hawlitschek, F., Notheisen, B., \& Teubner, T. (2018). The limits of trust-free systems: A literature review on blockchain technology and trust in the sharing economy. Electronic Commerce Research and Applications, 29, 50-63.

https://doi.org/10.1016/j.elerap.2018.03.005

Jouanjean, M.-A. (2019). Digital opportunities for trade in the agriculture and food sectors (OECD Food, Agriculture and Fisheries Papers No. 122). Paris: OECD Publishing. http://dx.doi.org/10.1787/91c40e07-en

Ma, M., Saitone, T. L., Volpe, R. J., Sexton, R. J., \& Saksena, M. (2019). Market concentration, market shares, and retail food prices: Evidence from the U.S. Women, Infants, and Children program. Applied Economic Perspectives and Policy, 41(3), 542-562. https://doi.org/10.1093/aepp/ppy016

Mettler, M. (2016). Blockechain technology in healthcare: The revolution starts here. Proceedings from IEEE 18th International Conference on e-Health Networking, Applications and Services (Healthcom), Munich, Germany. https://doi.org/10.1109/HealthCom.2016.7749510

Pazaitis, A., De Filippi, P., \& Kostakis, V. (2017). Blockchain and value systems in the sharing economy: The illustrative case of Backfeed. Technological Forecasting and Social Change, 125, 105-115. https://doi.org/10.1016/i.techfore.2017.05.025

Sander, F., Semeijn, J., \& Mahr, D. (2018). The acceptance of blockchain technology in meat traceability and transparency. British Food Journal, 120(9), 2066-2079. https://doi.org/10.1108/BFJ-07-2017-0365

Schahczenski, J. (2019). Knowing the real value of food: Blockechain in a new sustainable food economy. ATTRA Sustainable Agriculture Program, National Center for Appropriate Technology. Retrieved from https://attra.ncat.org/product/food-blockchain/

Smith, A. (1776). An inquiry into the nature and cause of the wealth of nations. 
Thompson, C. (2019, February 1). Blockchain: The answer to everything? [Blog post]. Retrieved from the Fairtrade Foundation website:

https://www.fairtrade.org.uk/Media-Centre/Blog/2019/February/Blockchain-The-Answer-to-Everything

Tripoli, M., \& Schmidhuber, J. (2018). Emerging opportunities for the application of blockechain in the agri-food industry. Rome and Geneva: Food and Agriculture Organization of the United Nations (FAO) \& International Centre for Trade and Sustainable Development (ICTSD). Retrieved from http://www.fao.org/documents/card/en/c/CA1335EN VeChain (2020). VeChain whitepaper, 2.0. Retrieved from https://www.vechain.org/whitepaper/ 